\title{
Evaluation of the Complex Modulus of Asphalt Mixes
}

\author{
O. Vacín* \& P. Bošek \\ Department of Civil Engineering, Czech Technical University, Prague, Czech Republic, \\ *Corresponding author: vacin@.fsv.cvut.cz
}

\begin{abstract}
The objective of this paper is to evaluate uniaxial loadings in compression for selected asphalt concretes. Cylindrical specimens were subjected to sinusoidal stresses at given frequencies and temperatures. The methodology of the test is discussed and a comparison is made between non-destructive indirect tensile testing and cyclic loading. The findings show that correlations can be made between these two methods.
\end{abstract}

KEY WORDS: Asphalt mixes, cylindrical specimens, uniaxial loading, frequency sweep.

\section{INTRODUCTION}

There are several methods for evaluating the performance properties of asphalt concretes. Although theories of such composite material have been well-known since the mid 1960s (eg. Monismith 1961, Sayegh 1965), only a few research centers worldwide carried out practical investigations of viscoelastic theories within the following two decades. Most of the reasons for this were rather practical. In order to observe real properties, the stress-to-strain ratio needs to be recorded at very short loading times and at various temperatures and sophisticated equipment is needed. The situation changed after the Superpave Performance Prediction system was introduced in the United States (Superpave, 1996). Nevertheless, it took several years for the Superpave System to be accepted at a national level and for new guidelines for asphalt concrete, based on performance testing, to be created by the National Cooperative Highway Research Program (NCHRP 465, 2002). These efforts led to the Mechanistic-Empirical Design Guide for New and Rehabilitated Pavement Structures (NCHRP 1-37A, 2004). The Guide, which is currently being evaluated by many state highway agencies, employs mechanisticempirical approaches, where uniaxial/triaxial cyclic loading serves as an important input into pavement design and prediction models. This test replaced previously used diametral test procedure, indirect tension test (NCHRP,1997).

Some of the findings have been used in European standards (EN 12 697-26, 2008), but the evaluation of uniaxial testing in compression has not been as successfully adopted by European agencies as, for example, the indirect tension test. This will lead to proper pavement thickness designs for a given period. Following such an approach, long-life pavements can be created on the basis of rational design with an optimized life-cycle cost. 


\section{EXPERIMENTAL GOAL}

In this study, the goal of the experimental plan was to apply unconfined cyclic loading with a diverse range of frequencies at various temperatures and in various magnitudes to selected mixtures. Also, appropriate response parameters that correlated most highly with the indirect tension test were taken into consideration. A comparison of moduli was done on Stone Mastic Asphalt (SMA).

\subsection{Material used}

Asphalt mixes with local bitumen and aggregates were selected for evaluation. Mixes, used as a surface and a binder course denoted as Stone Mastic Asphalt (SMA) SMA 11S is characterized as premium mix for road construction, table 1. Typically, such materials show good rutting resistance and a high stiffness modulus.

Table 1: SMA11S, gradation table, passing limits, mix properties

\begin{tabular}{|l|l|l|l|}
\hline SMA 11S & \multicolumn{2}{|l|}{ Gradation limits } \\
\hline sieve size & passing & $\begin{array}{l}\text { min. } \\
\text { passing }\end{array}$ & $\begin{array}{l}\text { max. } \\
\text { passing }\end{array}$ \\
\hline$(\mathrm{mm})$ & (percent) & (percent) & (percent) \\
\hline 11 & 91.0 & 90 & 100 \\
\hline 8 & 50.0 & 45.0 & 60.0 \\
\hline 4 & 28.0 & 26.0 & 38.0 \\
\hline 2 & 22.0 & 20.0 & 28.0 \\
\hline 0.125 & 13.0 & 9.0 & 15.0 \\
\hline 0.09 & 10.0 & 8.0 & 12.0 \\
\hline \multicolumn{2}{|l|}{ Binder content (percent) } & 6.2 \\
\hline \multicolumn{2}{|l|}{ Air voids (percent) } & 3.2 \\
\hline
\end{tabular}

\subsection{Specimen preparation}

All specimens were prepared under the same procedure. The asphalt binder was mixed with the aggregate skeleton according to the design charts listed in paragraph 2.1. Different mixing temperatures were based on the viscosities of the bitumen. A rolling wheel compactor was used for slab preparation. The amount of material needed was calculated using mold dimensions, the bulk and maximum specific gravities of the mix and the necessary target air voids. The height of the compacted slabs was set to $160 \mathrm{~mm}$. Two specimens were cored from each slab, as depicted in Figure 1, after cooling. The diameter of the cored specimens was $100 \mathrm{~mm}$. The edges were trimmed in order to achieve perpendicular planes for sinusoidal loadings.

The specimens for the indirect tension test were cut from the specimen, which had already been subjected to cyclic loading. This technique enables us to evaluate the same material under different loading conditions.
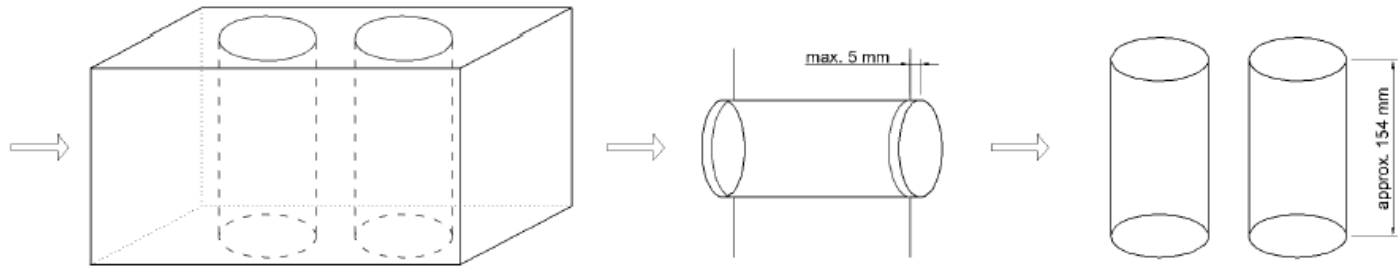

Figure 1: Procedure for specimen preparation (Bošek, 2010) 


\subsection{Cyclic modulus testing procedure}

Since this methodology is not well defined under the European standards, a modified AASHTO procedure was applied (AASHTO, 2004). The specimen was placed inside the loading apparatus (Figure 2) and was subjected to a series of stresses at different frequencies and temperatures (Figure 3). The applied load was adjusted for each temperature to achieve strain levels in order to capture linear viscoelastic behavior. The strain level was adjusted on the basis of experience and the stress response of the specimen between 50 and $150 \mu \mathrm{S}$.

The procedures for cyclic modulus can be summarized in the following steps:

- Prior to the test, four metal gage points were glued by epoxy to each specimen.

- Two LVDT extensometers were mounted on the specimen to capture the horizontal deformations measured on each side of the specimen.

- The test specimen was placed in the load frame. A seating load of five percent of the total load was applied to the test specimen to ensure proper contact of the upper loading head.

- The specimen was loaded by applying a repeated and continuous uniaxial sinusoidal load to obtain horizontal strains in the viscoelastic range.

- While loading, the computer software recorded all important characteristics as stress and strain sine waves in the time domain, calculating the modulus and other parameters.

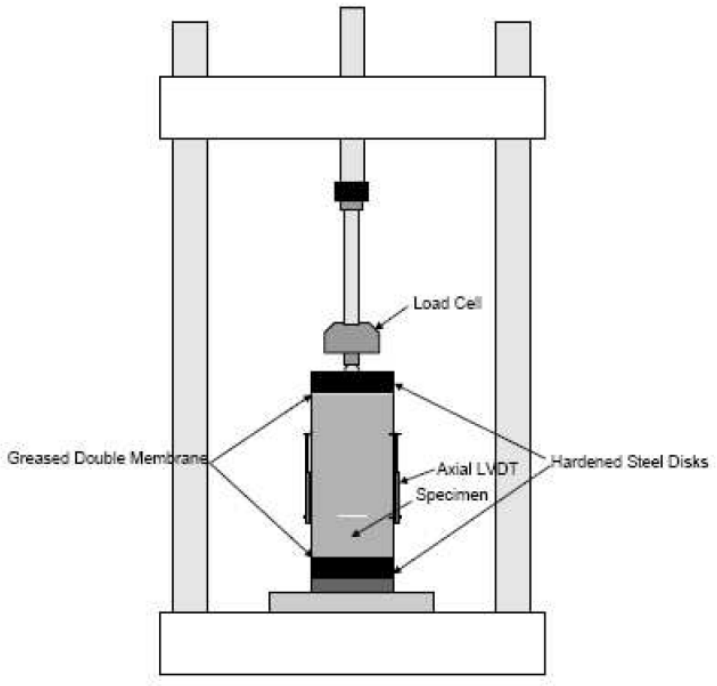

Figure 2: The cyclic loading scheme (AASHTO, 2004)

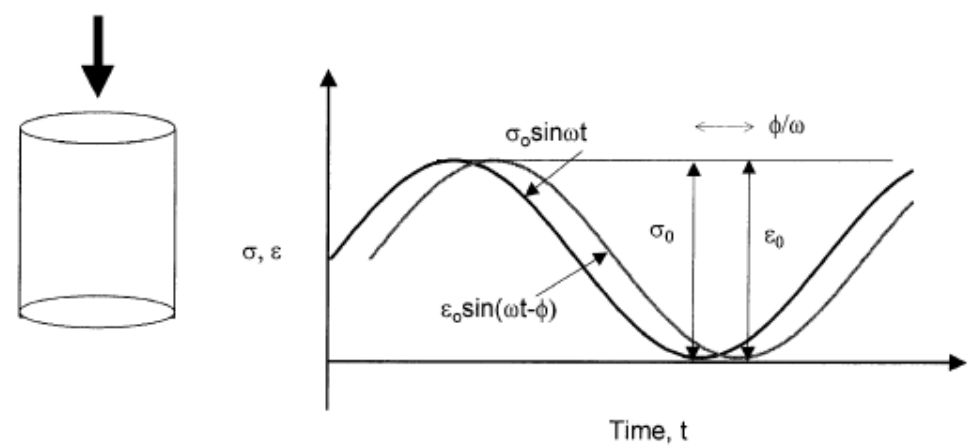

Figure 3: The principle of the stress - strain relationship (NCHRP 465, 2002) 


\subsection{Indirect tension test description}

The methodology for the indirect tension test is well established in Europe, thanks to the design devised at the University of Nottingham (Cooper \& Brown,1989), known as the Nottingham Asphalt Tester (NAT). Due to its simplicity, asphalt producers could easily and cheaply carry out their own tests and immediately see how their materials behaved in relation to others. This has led to a revolution in the asphalt industry, and NAT was later adapted by British standards (BS DD 213,1993) as well as European standards (EN 12 697-26, 2008). It is used regularly, evaluating materials in existing pavements. It has been used extensively in estimating the potential of various mixtures and binders, and serves as a tool in pavement design methodology (TP170, 2004).

The procedure is straightforward: a cylindrical specimen is placed under the loading frame and, while loaded, two vertical transducers measure the deflection on each side, created by stress, denoted as $\sigma_{x \max }$. The adjusted stiffness is calculated from five loading pulses,

Figure 4.

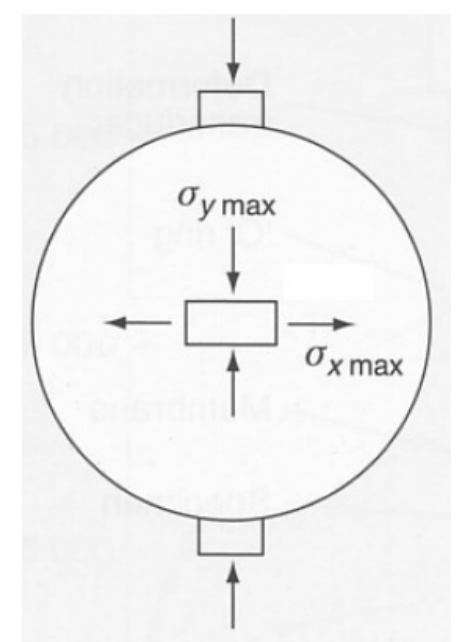

Figure 4: Schematic uniaxial loading in the indirect tension test

\section{RESULTS}

The stress-to-strain relationship under continuous sinusoidal loading for linear viscoelastic materials is defined by a complex number called the "complex modulus" $\left(E^{*}\right)$. The absolute value of the complex modulus, $\left|E^{*}\right|$, is defined as the cyclic modulus (dynamic modulus in the USA). The modulus is mathematically defined as the maximum (i.e., peak) dynamic stress $\left(\sigma_{\mathrm{o}}\right)$ divided by the peak recoverable axial strain $\left(\varepsilon_{\mathrm{o}}\right)$.

$$
|E *|=\frac{\sigma_{o}}{\varepsilon_{o}}
$$

On the other hand, the indirect tensile test has been used successfully to measure the stiffness modulus of asphalt concrete mixtures. The critical stress location by load is generally considered to be at the bottom of the asphalt concrete layer and immediately underneath the load, where the stress state is the longitudinal and transverse tension combined with vertical compression. The stress state in the vicinity of the center of the face of an indirect tension specimen is very similar to this stress state. Consequently, the complex 
modulus obtained by the indirect tensile test can also be compared to provide reasonable moduli correlations.

Stiffness $S_{m}^{\prime}$, adjusted to a load area factor of 0.60 , can be calculated as follows:

$$
S_{m}^{\prime}=S_{m} \times\left(1-0.322 \times\left(\log \left(S_{m}\right)-1.82\right) \times(0.60-k)\right)
$$

$S_{m}$ is the measured stiffness modulus, depending on the applied load, the horizontal deformation measured, the dimensions of the specimens, and Poisson's ratio. Proper determination of such a constant is rather vague for asphalt mixes. It is generally believed that the Poisson values lie between 0.20 and 0.45 , according to the temperature. The time of loading however, is not taken into consideration. Other research indicates that the ratio is also a function of the amount of polymers in the asphalt binder (Tech Brief, 2008).

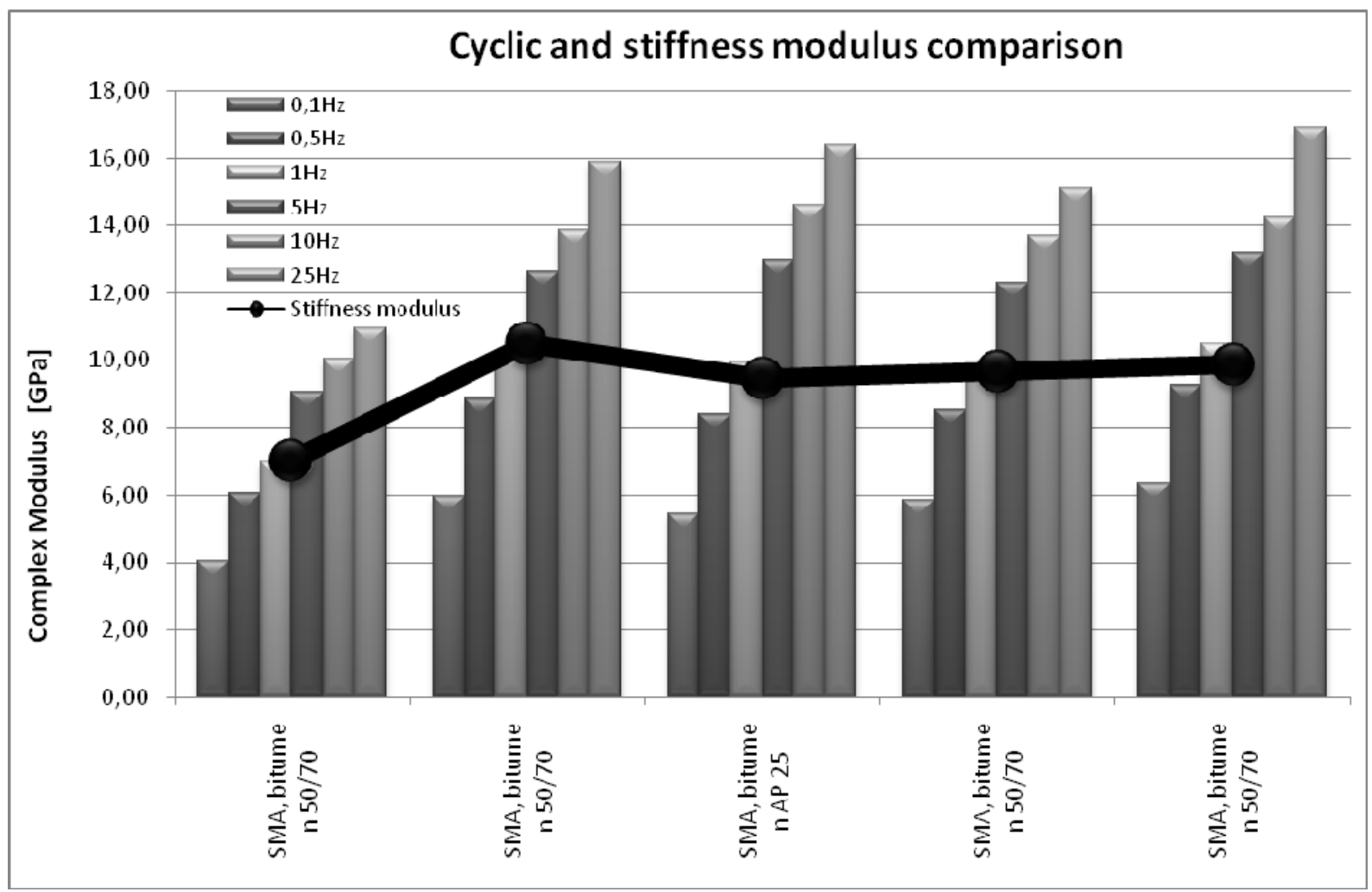

Figure 5: Comparison of complex modulus and stiffness measured by different procedures at $15^{\circ} \mathrm{C}$ (Bošek, 2010)

\section{CONCLUSIONS}

The results from the indirect tensile test indicate that the test is easy to perform and has the advantages of simplicity. However, proper determination of the input characteristics is needed for correct stiffness values. It is not recommended to test materials at temperatures above $30{ }^{\circ} \mathrm{C}$, and also thin specimens, due to the reduced stiffness of the asphalt mixes. This is because the stress differs from the theoretical formula for moduli calculation, while the stress in sample in the compression test is virtually unchanged. In this case, data obtained from the cyclic compression test are more straightforward, showing the real strain, stress - time response. A comparison of the two methods showed that there is a correlation 
between complex modulus and stiffness on selected asphalt mixes, Figure 5. Corresponding values were exhibited by the same moduli at a frequency of $1 \mathrm{~Hz}$ at a temperature of $15^{\circ} \mathrm{C}$. More research will be done on various mixes and various binders, using the same approach.

\section{ACKNOWLEDGEMENT}

This research was sponsored by the Academy of Sciences Czech Republic (GAČR) no. 103/07/P573.

\section{REFERENCES}

Monismith, C. L., 1962. Asphalt Paving Mixtures, Properties Design and Performance. Short course in asphalt paving technology 1961 - 1962, University of California, Berkeley.

Sayegh, G., 1965. Variation des Modules de Quelques Bitumes Purs et Bétons Bitumineux. Conférence au Groupe Français de Rhéologie, pp. 51- 74.

Superpave, 1996. Superpave Mix Design, Superpave series no. 2 (SP-2). Asphalt Institute.

NCHRP 465, 2002. Simple Performance Test for Superpave Mix Design. Transportation research board - national research council, National Academy Press Washington, D.C.

NCHRP 1-37A, 2004. Mechanistic-Empirical Design Guide for New and Rehabilitated Pavement Structures. Transportation research board - national research council, National Academy Press Washington, D.C.

NCHRP,1997. Laboratory Determination of Resilient Modulus for Flexible Pavement Design: Final Report. Transportation research board - national research council, National Academy Press Washington, D.C.

EN 12 697-26, 2008. Bituminous mixtures - Test methods for hot mix asphalt - Part 26: Stiffness.

Bošek P., 2010. Performance Properties of selected Asphalt Mixtures, MSc Thesis, CTU in Prague, 2010, Czech Republic.

AASHTO, 2004. TP 62-1, Determining Dynamic Modulus of Hot-Mix Asphalt Concrete Mixtures, American Association of State and Highway Transportation Officials $24^{\text {th }}$ Edition 2004, U.S.A.

Cooper, K.E. and Brown, S.F.,1989. Development of a simple apparatus for the measurement of the mechanical properties of asphalt mixes. Proc. Eurobitume Symposium, Madrid, pp. 494-498.

BS DD 213,1993. Method for determination of the indirect tensile stiffness modulus of bituminous mixtures. British Standards Institution, 15-Dec-1993, 16 pages.

TP 170, 2004. Navrhování vozovek pozemních komunikací. Ministry of Transport CR.

Tech Brief, 2008. Evaluation of Poisson's Ratio for Use in the Mechanistic Empirical Pavement Design Guide (MEPDG), FHWA-NJ-2008-004. 